\title{
PREFACE
}

\section{AN INTRODUCTION TO DENDROARCHAEOLOGY IN THE SOUTHEASTERN UNITED STATES}

\author{
HENRI D. GRISSINO-MAYER* \\ Laboratory of Tree-Ring Science, Department of Geography, The University of Tennessee-Knoxville, Knoxville, \\ Tennessee 37996, USA
}

\begin{abstract}
Dendroarchaeology has a discontinuous history in the Southeastern United States, mostly because of misconceptions (the Southeast is too mesic), bad sampling practices (no standard protocol exists for preserving prehistoric wood samples), and a lack of reference tree-ring chronologies long enough to date wood from the abundant prehistoric sites. The majority of archaeological applications in recent years has focused on the dating of historic sites and structures to verify the documented year(s) of construction largely in response to requests from historical agencies to verify when a particular structure was built. We have found that most structures are one to two generations younger than their reported date(s) of construction, but most agencies find this information useful as tree-ring dating lends historical credibility to any site. The future of dendroarchaeology in the Southeast is encouraging but many more trained experts are needed to meet the demand of dating historical structures and sites. Furthermore, once a sampling protocol becomes standardized for retrieving wood from prehistoric sites, the potential for absolute dating of these sites is enormous given that abundant wood is archived in locations throughout the Southeast.
\end{abstract}

Keywords: Tree-ring dating, dendroarchaeology, Southeastern U.S., construction history.

\section{INTRODUCTION}

Dendrochronology has a long history in both the southwestern United States (the birthplace of the discipline) and Europe (where foresters have exploited tree-ring information since the 1800s), but research in the southeastern U.S. has been discontinuous, largely because the forests of the region are more mesic and have been extensively cleared and impacted by humans. Further, many misconceptions still linger among scientists that tree-ring research simply is not possible in the southeastern U.S. because of high decomposition and decay rates and a lack of trees that are longlived or have sensitive patterns of tree rings to facilitate crossdating. For example, a standard protocol for sampling in situ wood from prehistoric archaeological sites has yet to be established by archaeologists working in the American South-

*grissino@utk.edu; Fax 865-974-6025; Telephone 865974-6029 east. This certainly makes tree-ring dating of wood extracted from these sites problematic especially because many times the wood has all but crumbled to oblivion when delivered to our laboratory (Figure 1). Each crumbled mass of former wood delivered to us represents potential information on site occupation history lost for good, although radiocarbon dates may still be possible.

\section{A BRIEF HISTORY}

Early suggestions and attempts at tree-ring dating, especially for archaeological purposes, can be traced back to 1798 when Reverend Manasseh Cutler suggested that a prehistoric mound site in Ohio could be dated by counting the rings on living trees that were then growing on the mound to determine a minimum age (Cutler and Cutler 1987). Later, Florence Hawley would use her training in dendrochronology obtained from Andrew Ellicott Douglass at the University of 


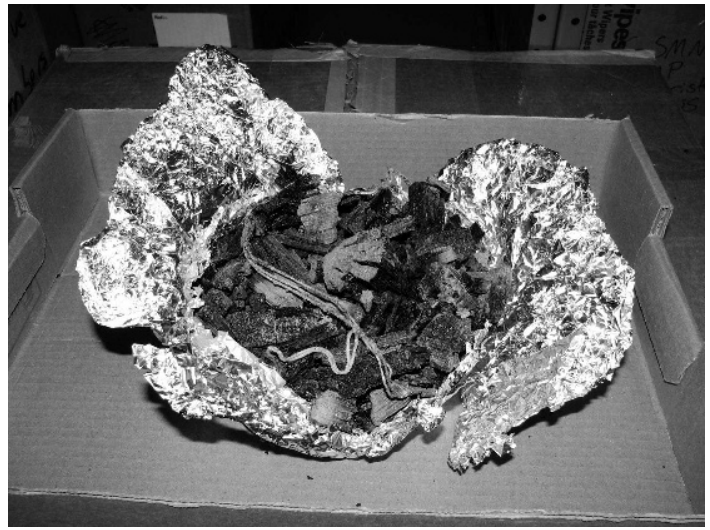

Figure 1. A sample from the King Site, a prehistoric site in northwestern Georgia analyzed by archaeologists from 1973 to 1974 (Hally 1988). Originally wrapped with twine and encased in aluminum foil, this sample has no chance of having its treering record examined. The site did yield, however, 15 measured and crossmatched series from 9 pieces of wood with an interseries correlation of 0.59

Arizona to establish the first tree-ring laboratory in the eastern U.S. at the University of Chicago in 1933 (Nash 1999). Her seminal research would confirm that tree-ring dating and especially the technique of crossdating could be accomplished east of the Mississippi River, although she had difficulty obtaining confirmation from a very-busy and perhaps unconvinced A.E. Douglass (during this period, all tree-ring dates had to be confirmed by Douglass). By 1935, she claimed to have established a chronology from eastern red cedar (Juniperus virginiana L.) growing in eastern Tennessee back to an astounding A.D. 1295 in just a matter of $2+$ years, a feat that even by today's standards would be considered extraordinary. Continued frustration and especially gender bias likely contributed to her eventually abandoning dendrochronology altogether soon after 1943 to focus again on southwestern archaeology at the University of New Mexico. Curiously, Hawley's former colleague and eventual adversary, Roy Lassetter (Nash 1999), successfully dated several 19th Century log cabins in eastern Tennessee using tree-ring dating (Lassetter 1938), and can be credited as the first to date historic structures in the Southeastern U.S. via dendrochronology.

Sporadic attempts at tree-ring dating in the Southeastern U.S. occurred during the next 35 to
40 years, but none represented archaeological applications. By the 1970s, interest in dendrochronology applied in the southeastern U.S. was renewed (Estes 1970; Bowers 1973; Cleaveland 1975). Bowers and Grashot (1976) attempted to date the two log structures at the First Hermitage, the home of President Andrew Jackson and his family in the early 1800 s outside Nashville, Tennessee, but their findings were mostly inconclusive. Finally, Stahle (1978) performed the first successful dating of log structures since Lassetter in 1938, exactly 40 years later, but the attention of Stahle and his colleagues (at what would later become the University of Arkansas Tree-Ring Laboratory) turned to research areas other than archaeology in the 1980s. By the 1990s and early 2000s, studies mention the use of tree-ring dating applied to historic sites in the southeastern U.S. by Herman J. Heikkenen and his colleagues from Dendrochronology Inc. based in Blacksburg, Virginia (Sandbeck 1992; McCrea 1995; Olmert and Chappell 2002) but, to the best of my knowledge, this team has never published their findings, and their dates are difficult to verify. Anderson et al. (1995) were the first to use the tree-ring record to make inferences on past drought and its impact on carrying capacity of prehistoric Native American societies in the Southeastern U.S., but this lone study represents, to this day, the only application of tree rings for understanding prehistoric cultures in the Southeast. Stahle et al. (1998) and Blanton (2000) used bald cypress (Taxodium distichum (L). Rich.) treering data and found that an unprecedented drought was a significant factor in the collapse of the Jamestown Colony in Virginia between 1607 and 1612.

By the late 1990s, my return to the southeastern U.S. from a 9-year association at the University of Arizona provided opportunities to again explore the potential of tree-ring dating applied to historic and prehistoric sites and structures. Actually, I did not have to look too far as a steady stream of requests for tree-ring dating began soon after my arrival. Later at the University of Tennessee-Knoxville, graduate students became readily available and were eager to learn and use dendrochronology to date structures 
throughout the Southeast (Mann 2002; Reding 2002; Wight and Grissino-Mayer 2004). Since 2000, we have been fortunate to become involved with many intriguing, challenging, and controversial cases for which tree-ring dating has proven useful and definitive (see Grissino-Mayer and van de Gevel 2007; Henderson et al. 2009, this volume; and Slayton et al. 2009, this volume). This volume illustrates not only the diversity of issues that can be addressed, but more so the interdisciplinary nature of dendrochronology. The lead authors on all articles were or still are graduate students in three departments here at the University of Tennessee-Knoxville: Geography, Earth and Planetary Sciences, and Anthropology. Besides the many structures dated via tree rings outlined in this volume, we have dated nearly 30 other structures from Delaware to Florida.

\section{THE NEED FOR DENDROARCHAEOLOGY IN THE SOUTHEAST}

In general, we find that approximately twothirds of the historic structures are in fact younger than their documented year(s) of construction by at least one to two generations (25 to 50 years). For example, the Rocky Mount Historic Site north of Johnson City, Tennessee, was reportedly built between 1770 and 1772, but our detailed analyses of $88 \operatorname{logs}$ in two structures show these were built instead between 1826 and 1830 (Grissino-Mayer and van de Gevel 2007; GrissinoMayer et al. 2008). The Marble Springs Historic Site features two log houses, one of which was once thought to belong to Tennessee's first governor, John Sevier, but the house was built over 20 years after his death in 1815 (see Slayton et al. 2009, this volume). Two reasons can be proffered to explain this. First, oral history tends to make objects older than they actually are (albeit often this is unintended), i.e. what we call "false antiquity". It is human nature to want objects (especially historic sites and structures) to be old, and what was once a $\log$ cabin built by a greatgrandfather eventually becomes a log cabin built by a great-great-grandfather. Second, sites with considerable antiquity and history breed tourism and this stimulates local economies. Considerable pressure mounts to list a historic house on the National Park Service's National Register of Historic Places, and attaching a house to a famous person or event in U.S. history may require pushing back the antiquity of the house a few decades.

Occasionally, however, the results from the tree-ring dating substantiate what was already known from previous archaeological investigations, which also sometimes refute the reported year(s) of construction for some sites. For example, a Mean Ceramic Date (South 1977) of 1810 had been calculated for the Hoskins House in Greensboro, North Carolina (Stine 2005) and we found that the house was constructed with trees cut between 1811 and 1813 (Henderson et al. 2009, this volume). Elijah Ellerbusch (personal communication, 22 Feb 2008) used 48 ceramics and calculated a Mean Ceramic Date of 1833 for the Rocky Mount Historic Site and this site in fact dates between 1826 and 1830. Mann et al. (2009, this volume) analyzed a blockhouse reportedly built in 1787. Instead, the logs from this structure were cut in 1859 and 1860, which substantiated the calculated Mean Ceramic Date of 1852. Jones (2002) assigned a date for Alfred's Cabin at The Hermitage of " $c a$. 1840s" based on architectural details, and this cabin in fact was built from trees cut between 1841 and 1843. These results demonstrate first the efficiency of methods used by historical archaeologists, and secondly the need for corroboration from tree-ring dating. Together, these two techniques can provide convincing proof of the antiquity (or lack of antiquity) of a site or structure.

\section{DIFFERENCES IN SOUTHEASTERN DENDROARCHAEOLOGY}

Conducting dendroarchaeology in the Southeast differs considerably from dendroarchaeology practiced elsewhere in the U.S. and three key issues need clarification. First, some question whether what we do is "dendroarchaeology" as opposed to just "dendrochronology". Much of what we practice is relevant to the field of historical archaeology (Orser 2004) and our results play a large and growing part in helping under- 
stand past lifeways and traditions of the diverse cultures (e.g. enslaved Americans), industries (e.g. saltpeter mining), and individuals (e.g. pioneer settlers) who once lived or operated in the Southeast. If all we reported were the dates provided by the tree rings and no information on the meaning of these dates, then this would have been a short and rather boring volume.

Second, the visual level of congruency among tree-ring series from samples collected in the Southeast is quite different from the visual agreement seen in tree-ring series from other areas of the world, especially those from the Southwestern U.S. Recognition of tree-ring patterns in the Southeast relies heavily on the few narrow marker rings evident across series, such as the 1774 very narrow marker ring seen in oak in northeastern Tennessee, western North Carolina, and southwestern Virginia. Hence, visual agreement across tree-ring series will not be as striking as that seen in samples from the Southwestern U.S., for example. Our crossdating is always verified statistically using COFECHA and rigidly and carefully diagnosed and inspected before we release any dates for any one structure. After all, our reputation, as well as that of the entire field, is at stake when we release dates.

Third, the methods we have painstakingly developed for tree-ring samples collected from the Southeast diverge only slightly from the classical methods taught to dendrochronologists. We find it more expedient and efficient to first measure the rings on our core and cross-section samples and then input these measurement series into COFECHA to provide a first pass at crossdating. Most of the cores were extracted from oak timbers, and oak rarely has problematic rings: "[I]t is extremely rare to find an oak which has missed a year's growth or which shows two distinct rings in a single year" (Baillie 1982). More often than not, COFECHA will instantly show the possible dating against the reference tree-ring chronology, especially when the outermost rings from many series cluster within a short time frame, indicating a common interval of tree harvesting for construction. The series are then graphically aligned using primarily scatter plots (but we still teach and use skeleton plotting) against the reference chronolo- gies to verify the suggested placement. On rare occasions, the graphical placements were not convincing and the series were not included in further analyses. Although skeleton plots are still useful, the lower degree of tree sensitivity in the Southeast renders them less useful than scatter plots, which accentuate low-frequency trends that are useful in tree-ring dating. This observation was first echoed by Baillie (1982, p. 79): “'A skeleton plot] is only of use where the trees are extremely sensitive, as in semi-arid regions. With deciduous trees, skeleton plots neglect a considerable amount of information stored in the relatively complacent rings between signatures."

\section{THE FUTURE OF SOUTHEASTERN DENDROARCHAEOLOGY}

The future of dendroarchaeology in the Southeastern U.S. is bright and encouraging. No shortage exists of potential projects that involve tree-ring dating of historic structures, and these can form the nucleus of projects that enhance the training of our future dendrochronologists. My laboratory, sadly, has to turn down more potential projects than it accepts because we simply do not have the human resources to devote to what would amount to be full-time research in dendroarchaeology. However, more and more trained dendrochronologists have established laboratories in the Southeastern U.S. that can conduct tree-ring analyses. In addition to the University of Tennessee-Knoxville and the University of Arkansas, the following institutes in the Southeast now have facilities for dendrochronological research: Eastern Kentucky University, the University of West Georgia, West Virginia University, the University of North Carolina-Greensboro, Appalachian State University, and Virginia Polytechnic Institute and State University (Virginia Tech) (apologies if I have overlooked your institute).

Lastly, perhaps the most overlooked potential for applying tree-ring dating in the Southeastern U.S. involves the dating of prehistoric sites, begun initially by Florence Hawley in the 1930s. Three key problems need to be overcome. First is the need to educate archaeologists throughout the Southeast that tree-ring dating is possible and that 
it can be attempted on wood recovered from prehistoric sites. Second, a standard sampling protocol must be established to ensure that wood samples from prehistoric sites are preserved so that tree-ring dating can be attempted. This may involve both chemical and physical treatment of the wood, perhaps using wood preservation techniques now applied for both waterlogged wood and wood found in historic structures that has degraded and requires treatment (Keene 1977; Krusic and Hornbeck 1989; Coles 1990). We still find wood samples excavated in the early 20th Century from prehistoric sites here in the Southeast that are encased in paraffin and which had been treated first with a mixture of paraffin and gasoline (Hall 1939) as outlined in 1941 by the Division of Anthropology at the University of Tennessee-Knoxville (Lewis and Kneberg Lewis 1995). Many samples, sadly, were not preserved adequately and have all but disintegrated (Figure 1).

Lastly, just as Douglass accomplished on June 22, 1929 at Show Low, Arizona (Nash 1999), we here in the Southeast need to bridge the gap between a chronology of living eastern red cedar trees that currently extends back to the late 1300 s (Cook, unpublished data; see Lewis et al. 2009, this volume) and the tree-ring chronologies available from wood excavated from prehistoric sites. Considerable amounts of wood are archived in many museums and laboratories here in the Southeast, including here at the McClung Museum on the University of Tennessee-Knoxville campus. Efforts are currently underway in a collaborative effort between the Laboratory of Tree-Ring Science and colleagues in the Department of Anthropology (Professors David Anderson and Jan Simek and graduate students Bobby Braly and Shannon Koerner) to first retrieve then crossdate the wood, thus providing, for the first time ever, absolute dates for prehistoric sites here in the Southeastern U.S. Hopefully, one day soon, these results will pay a long-overdue tribute to the foresight and legacy of Florence Hawley.

\section{REFERENCES}

Anderson, D. G., D. W. Stahle, and M. K. Cleaveland, 1995. Paleoclimate and the potential food reserves of Mississippian societies: A case study from the Savannah River Valley. American Antiquity 60:258-286.

Baillie, M. G. L., 1982. Tree-Ring Dating and Archaeology. University of Chicago Press, Chicago, IL.

Blanton, D. B., 2000. Drought as a factor in the Jamestown Colony, 1607-1612. Historical Archaeology 34:74-81.

Bowers, L. J., 1973. Tree-Ring Dating of the Bald Cypress (Taxodium distichum (L.) Rich.) in the Lower Mississippi Valley, M.S. thesis, Arkansas State University, Jonesboro, AK.

Bowers, L. J., and D. L. Grashot, 1976. Results of the First Hermitage dendrochronological study. In An Archaeological and Historical Assessment of the First Hermitage, edited by S. D. Smith, pp. 271-281. Division of Archaeology, Tennessee Department of Conservation, and The Ladies Hermitage Association, Nashville, Tennessee.

Coles, J. M., 1990. Waterlogged Wood: Guidelines on the Recording, Sampling, Conservation, and Curation of Waterlogged Wood. Ancient Monuments Laboratory, English Heritage, London.

Cleaveland, M. K., 1975. Dendroclimatic Relationships of Shortleaf Pine (Pinus echinata Mill.) in the South Carolina Piedmont, M.S. thesis, Clemson University, Clemson, SC.

Cutler, W. P., and J. P. Cutler, 1987. Note to Dr. Cutler's charge at the ordination of Rev. Daniel Story, August 15, 1798. In Life, Journals, and Correspondence of Rev. Manasseh Cutler, LL.D., pp. 14-17. Ohio University Press, Athens, OH.

Estes, E. T., 1970. Dendrochronology of black oak (Quercus velutina Lam.), white oak (Quercus alba L.), and shortleaf pine (Pinus echinata Mill.) in the Central Mississippi Valley. Ecological Monographs 40:295-316.

Grissino-Mayer, H. D., and S. L. van de Gevel, 2007. Tell-tale trees: Historical dendroarchaeology of $\log$ structures at Rocky Mount, Piney Flats, Tennessee. Historical Archaeology 41:32-49.

Grissino-Mayer, H. D., L. B. LaForest, and S. L. van de Gevel, 2008. Further analyses on the history of log structures at the Rocky Mount Historic Site, Piney Flats, Tennessee from treering and documentary evidence. Final Report, Tennessee Historical Commission, Nashville, Tennessee; 76 pp.

Hall, Jr., E. T., 1939. A method of obtaining a plane surface on charcoal. Tree-Ring Bulletin 5:31.

Henderson, J. P., H. D. Grissino-Mayer, S. van de Gevel, and J. L. Hart, 2009. The historical dendroarchaeology of the Hoskins House, Tannenbaum Historic Park, Greensboro, North Carolina, U.S.A. Tree-Ring Research 65:37-45.

Keene, S., 1977. An approach to the sampling and storage of waterlogged timber from excavations. Conservator 1:8-11.

Hally, D. J., 1988. Archaeology and settlement plan of the King Site. In The King Site: Continuity and Contact in SixteenthCentury Georgia, edited by R. L. Blakely, pp. 3-16. University of Georgia Press, Athens, GA.

Jones, R., 2002. The Hermitage Cultural Resources Inventory: Alfred's Cabin. Report on file at The Hermitage, Nashville.

Krusic, Jr., P. J., and J. W. Hornbeck, 1989. Preserving decayed wood samples for tree-ring measurement. Tree-Ring Bulletin 49:23-27.

Lassetter, R., 1938. A Dendrochronological Investigation in the Clinch River Drainage, Tennessee, M.A. thesis, University of Tennessee, Knoxville. 
Lewis, D. B., W. L. Nelson, H. D. Grissino-Mayer, E. R. Cook, and R. D. Jones, 2009. Dendrochronological dating of eastern red cedar (Juniperus virginiana L.) logs from Alfred's Cabin, The Hermitage, home of President Andrew Jackson. Tree-Ring Research 65:47-55.

Lewis, T. M. N., and M. D. Kneberg Lewis, 1995. Manual of field and laboratory techniques employed by the Division of Anthropology, University of Tennessee, Knoxville, Tennessee. In The Prehistory of the Chickamanga Basin in Tennessee, edited by Lynne P. Sullivan, pp. 603-658. The University of Tennessee Press, Knoxville.

Mann, D. F., 2002. The Dendroarchaeology of the Swaggerty Blockhouse, Cocke County, Tennessee, M.S. thesis, University of Tennessee, Knoxville.

Mann, D. F., H. D. Grissino-Mayer, C. H. Faulkner, and J. B. Rehder, 2009. From blockhouse to hog house: The historical dendroarchaeology of the Swaggerty Blockhouse, Cocke County, Tennessee, U.S.A. Tree-Ring Research 65: 57-67.

McCrea, W. J., 1995. Dendrochronology: A new research tool. North Carolina Preservation 99:3-7.

Nash, S., 1999. Time, Trees, and Prehistory: Tree-Ring Dating and the Development of North American Archaeology, 1914 1950. University of Utah Press, Salt Lake City.

Olmert, M., and E. Chappell, 2002. Peering into the rings of grain. Colonial Williamsburg 24:74-79.
Orser, Jr., C. E., 2004. Historical Archaeology. Prentice Hall, Upper Saddle River, NJ.

Reding, W. M., 2002. Assessment of Spatial and Temporal Patterns of Log Structures in East Tennessee, M.S. thesis, University of Tennessee, Knoxville.

Sandbeck, P. B., 1992. Dendrochronology: A new tool for dating historic structures. Tributaries 2:26-29.

Slayton, J. D., M. R. Stevens, H. D. Grissino-Mayer, and C. H. Faulkner, 2009. The historical dendroarchaeology of two log structures at the Marble Springs Historic Site, Knox County, Tennessee. Tree-Ring Research 65:23-36.

South, S., 1977. Method and Theory in Historical Archaeology. Academic Press, New York.

Stahle, D. W., 1978. Tree-Ring Dating of Selected Arkansas Log Buildings, M.A. thesis, University of Arkansas, Fayetteville.

Stahle, D. W., M. K. Cleaveland, D. B. Blanton, M. D. Therrell, and D. A. Gay, 1998. The Lost Colony and Jamestown droughts. Science 280:564-567.

Stine, L. F., 2005. Results of 2004 archaeological testing at Tannenbaum State Park, 31GF413, Greensboro, North Carolina. Final Report submitted to the City of Greensboro's Tannenbaum Historic Park, the Guilford Battleground Company, and the Tannenbaum-Sternberger Foundation.

Wight, G. G., and H. D. Grissino-Mayer, 2004. Dendrochronological dating of an Antebellum Period house, Forsyth County, Georgia, U.S.A. Tree-Ring Research 60:91-99. 